\title{
A Conceptual Model for the Development and Assessment of Teamwork
}

\author{
Stephanie G. Adams, Ph.D., Laura C. Simon Vena, \\ Bianey C. Ruiz-Ulloa and Fernando Pereira \\ University of Nebraska-Lincoln
}

Abstract

This article presents a newly developed conceptual model to assist in the development of effective teams; to assess team effectiveness and to measure the growth of individuals working in teams. This model, to be carried out in three phases, will reveal that when individuals have an effective teaming experience the following will occur: a) individually, team members will grow in their understanding of teaming constructs; b) the team as a whole will grow in their understanding of team constructs and c) proper synergy of task and team processes will occur.

The model, which examines the essential components in building teams and determining whether or not teams are effective, starts with the assessment of the individual regarding their understanding of teams and their attitude towards teamwork. This assessment begins prior to starting the task and prior to any contact with fellow team members. The next step is the collective assessment of the team with regards to the teams' attitudes about teaming and the use of teams and the teams' ability to manage the seven constructs introduced here in the model. The objective of the pre-assessment phase is to provide a starting point to assist in measuring the growth of individuals and the growth of teams. In this model, training and task performance are thought of as treatments and post-assessment is useful in measuring growth after the completion of the task.

Introduction

Today's world is witnessing an unstoppable growth in the use of teams both in industry and in academia. Many organizations are moving toward a structure based on teams or groups rather than the traditional emphasis on individual contributors. However, employers find engineering students are not effectively prepared to work in teams and keep up with the fast changing environment created by technology. Despite industrial trends and employers' expectations, a gap exists between the mastery of teaming skills expected and those demonstrated by new engineering graduates. Employers expect college students to possess these skills and often complain that college graduates have not learned the team approach to problem solving. ${ }^{1}$

Employers, along with the Accreditation Board for Engineering and Technology (ABET), expect better preparation in these areas to be incorporated into the engineering curriculum at the college and university level. ${ }^{1,2}$ ABET stated in EC 2000, Criteria for Accrediting Programs, that one program outcome and assessment measure for engineering programs is to demonstrate that their graduates have an ability to function on multi-disciplinary teams. ${ }^{2}$ 
Unfortunately, many colleges and universities have not been able to show that the use of teams is enhancing teaming skills and learning. This ABET requirement and industry's need for teamwork bring to light a series of questions for engineering educators. The first question is what does it mean to function on a multi-disciplinary team? Secondly, what should be used to measure students' ability to do so? Next, how will teaming in the classroom be used to enhance this ability? And finally, what role effect does teamwork have on the enhancement of learning? The answers to these questions are paramount if engineering educators are to successfully incorporate teams into the engineering classroom.

To begin answering the aforementioned questions regarding teamwork, a conceptual model with universal application, for the development and facilitation of effective teaming has been developed. The model is based on the following ideas: 1) individuals must understand and be able to demonstrate their understanding in areas leading to team effectiveness; 2) a collective team of individuals must also understand and be able to demonstrate their understanding in areas leading to team effectiveness; and 3) measurement of understanding must occur both individually and collectively prior to and at the conclusion of the task.

According to Brannick and Prince, before a group of individuals can function effectively as a team, the members must have the technical knowledge and skills to perform their own tasks. ${ }^{3}$ Afterall, effective teamwork requires team members who have positive attitudes toward the team and its task, have been provided adequate direction and support for accomplishing team goals, and know their responsibilities and those of other team members with whom they interact. Therefore, efforts to improve team performance must focus on the performance of individuals. ${ }^{3}$

Specifically, measures of effectiveness should include both the individual and team unit of analysis, capture the process as well as outcome, describe and diagnose performance and help to provide knowledge of the results to the team for developmental feedback. ${ }^{3}$ An alignment of the needs of the individual, the dynamics of the team and the requirements of the task will produce a high-performing, synergistic team. The conceptual model for the development and facilitation of effective teaming was developed with this in mind.

\section{Explanation of the Model}

Conceptually, the model is designed to be universal in use, however our initial work will center on academic settings. The goals for the academic use of the model depicted in Figure 1 are as follows:

1) to assist with the facilitation of teamwork in the classroom;

2) to assist with the measurement of individual growth to learning a subject and learning how to work in a team; and

3) to assist with the measurement of teamwork effectiveness in enhancing quality results.

The model shown begins with the administration of a pre-assessment instrument for both individual members and the team, collectively, on their attitudes regarding teaming, their experiences with teaming and their proficiency with the characteristics leading to an effective team experience. The pre-assessment is being administered to establish a baseline for training

"Proceedings of the 2002 American Society for Engineering Education Annual Conference \& Exposition Copyright (C) 2002, American Society for Engineering Education” 
purposes and growth measurement. It is important, when trying to understand team behavior, to remember that a group is a system of associations and that if the nature of those associations is changed, the behavior of the group has no choice but to follow the directions dictated by those connections, and that no individual in the group has to change to elicit a new behavior. ${ }^{4}$

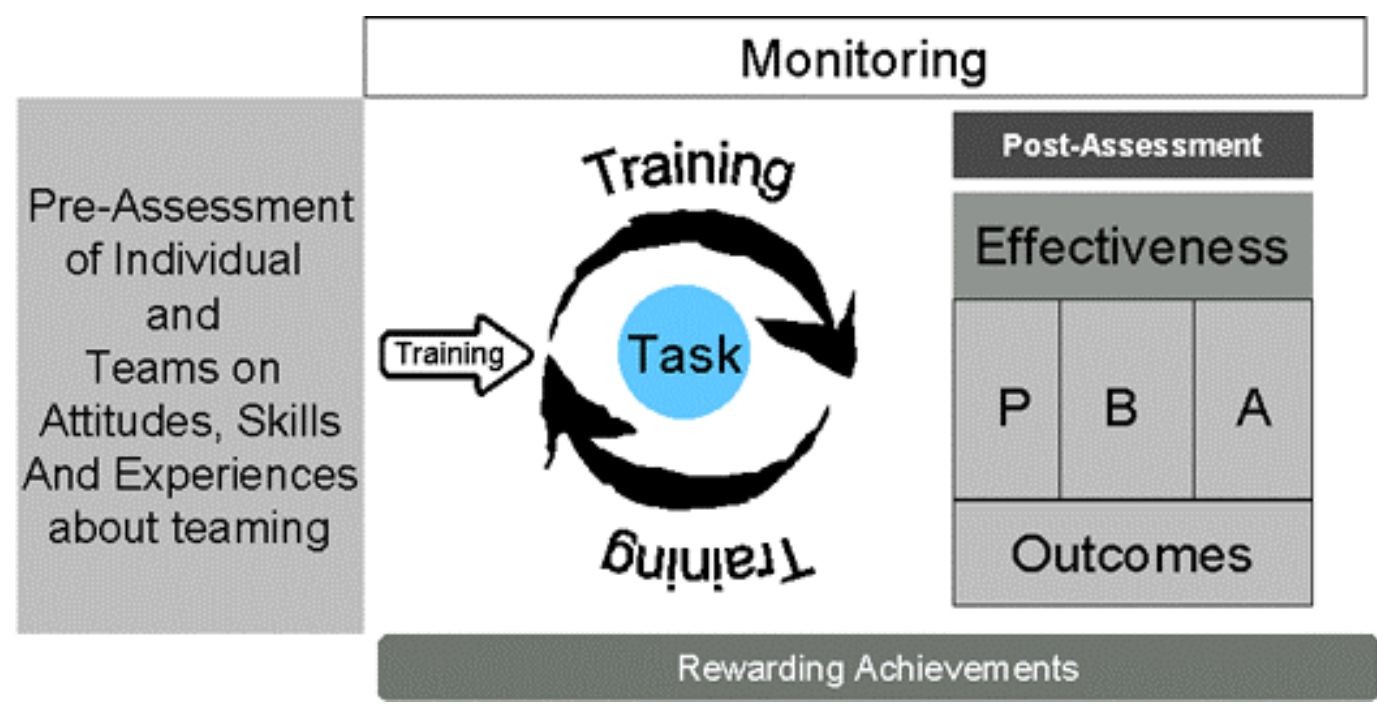

Figure 1.

As individuals and teams complete the pre-assessment period, training should be provided to all teams prior to their work on the task. The convener of the teams sets forth the task to be completed. Training in subjects such as: role clarification, effective listening \& communication, conflict resolution, running effective meetings, decision making techniques, setting goals, and proper evaluation techniques is recommended. Also, at this point monitoring should begin.

During the monitoring process, team facilitators, conveners, coaches, instructors, etc. should observe the dynamics of the team, the attitudes of the members throughout the teaming process and the stages of development the team exhibits. Monitoring should be objective and should be done qualitatively. The team convener should observe the teams in action as well as query members via focus groups and interviews as to their experiences. This information will be beneficial in evaluating the behaviors and attitudes of team members. As the team goes through the task performance process, training should be continuously provided as needed.

Also, during this time it is important to reward team members. Rewards are typically given upon completion of a task or project, but this model promotes rewards throughout the teaming process for meeting major deadlines, meeting them ahead of schedule or other acts that demonstrate success by the team. Rewards might consist of a "pat on the back" for a job well done, a certificate of achievement, a pizza party for all team members, verbal acknowledgement or some other motivational event. Once the task is completed a post-assessment should be conducted to measure the effectiveness of the team. 
Highly effective teams exhibit certain characteristics. A review of the literature produced numerous characteristics for consideration. The hypothesis for this model is that the following seven characteristics (to be referred to in the remainder of this article as constructs) common purpose, clearly defined goals psychological safety, role clarity, mature communication, productive conflict resolution, and accountable interdependence are the most critical for an effective teaming experience in the classroom. Descriptions of each construct follows:

Common purpose is the main objective of the team, which should be understood and shared by all team members. Common purpose should lead to the development of the team's goals. Successful teams shape their purposes in response to a demand or opportunity put in their path. ${ }^{5}$ This helps teams get started by broadly framing the convener's expectation.

Clearly defined goals are quantifiable and commonly agreed upon statements that define the actions to be taken by the team. The attainment of specific goals helps teams maintain their focus.

Psychological safety is the shared belief that the team is safe for interpersonal risk taking. ${ }^{6}$ Psychological safety leads to a team climate characterized by interpersonal trust and mutual respect in which people are comfortable being themselves. Psychological safety is a sense of confidence that the team will not embarrass, reject or punish someone for speaking up.

Role clarity is the team members' common understanding of each individuals expected role. The presence of role clarity minimizes misunderstandings regarding task assignments.

Mature communication refers to team members' ability to:

1. articulate ideas clearly and concisely,

2. give compelling reasons for their ideas,

3. listen without interrupting,

4. clarify what others have said,

5. provide constructive feedback.

Mature communication among team member ensures a higher level of understanding.

Productive conflict resolution refers to the procedures and actions taken when a conflict occurs that lead to results such as:

1. facilitating the solution of the problem,

2. increasing the cohesiveness among team members,

3. exploring alternative positions,

4. increasing the involvement of everyone affected by the conflict and

5. enhancing the decision-making process. ${ }^{7}$

Accountable interdependence is the mutual dependence that all team members have regarding the quality and quantity of each individual's work within the team. Mutual dependence generates a shared sense of security.

In order to measure these constructs we must look at the process of completing the task and the satisfaction of the team members. Task completion and satisfaction can be furthered 
studied by examining the relationship between performance, behavior and attitude to effectiveness. The hypothesis of the model regarding team effectiveness is that effectiveness (E) is defined as a function of team performance (P), members' behaviors $(\mathrm{B})$ and members' attitudes (A) and can be represented by the equation, shown in Figure 2.

$$
\mathrm{E}=f(\mathrm{P}, \mathrm{B}, \mathrm{A})
$$

Figure 2. Mathematical Representation of Effectiveness

Future research will be conducted to determine the exact relationship between performance, behavior and attitude with effectiveness. Performance considers the extent to which the outputs meet the standards of quantity, quality and timeliness of those who use the product or receive the service. ${ }^{8}$ Behavior considers the extent to which the team experience contributes to the growth and personal well being of team members. ${ }^{8}$ Attitude is concerned with examining how the process of carrying out the work enhances the capability of members to work together interdependently in the future. ${ }^{8}$

For the purposes of this model the outcomes for performance, behavior and attitude along with the tools for measurement are shown in Table 1.

\begin{tabular}{|c|c|c|}
\hline & Outcomes & Tool \\
\hline $\begin{array}{l}\text { Performance }(P) \\
\text { (on the assigned task) }\end{array}$ & $\begin{array}{l}\text { - } \text { Knowledge about the } \\
\text { - } \text { Subject } \\
\text { - } \text { Quality of the results } \\
\text { - } \quad \text { Quantity of the results } \\
\text { - }\end{array}$ & $\begin{array}{l}\text { - Project report } \\
\text { - } \text { Project presentation } \\
\text { - } \text { Knowledge test (for } \\
\text { declarative and procedural } \\
\text { knowledge) } \\
\text { - External assessment } \\
\text { - Concept map } \\
\text { - Vee diagram } \\
\text { - Case studies }\end{array}$ \\
\hline $\begin{array}{l}\text { Behavior }(B) \\
\text { (as a team) }\end{array}$ & $\begin{array}{l}\text { Behaviors identified with } \\
\text { each of the constructs } \\
\text { contributing to team } \\
\text { effectiveness }\end{array}$ & $\begin{array}{ll}\text { - } & \text { Direct observations } \\
\text { - } & \text { Interview } \\
\text { - } & \text { Video tapes }\end{array}$ \\
\hline $\begin{array}{l}\text { Attitude (A) } \\
\text { (toward teamwork) }\end{array}$ & $\begin{array}{l}\text { - Willingness to continue } \\
\text { working in team } \\
\text { - Satisfaction for the } \\
\text { teamwork experience and } \\
\text { the work done }\end{array}$ & $\begin{array}{ll}\text { - } & \text { Questionnaire } \\
\text { - } & \text { Interview } \\
\text { - } & \text { Video tapes }\end{array}$ \\
\hline
\end{tabular}

Table 1. Outcomes of Model

Summary

The authors recognize that there are other models of effective teamwork, i.e. The Team Developer by McGourty and the Team Performance Questionnaire by Reichmann, however feel 
this model is different because of the first build individuals and then build teams approach and the selection of the seven constructs previously identified.

Development, testing and validation of the model will occur in three phases. The first phase consists of the development of a questionnaire, to be called the Team Effectiveness Questionnaire (TEQ). The instrument is used to measure performance and attitude. To date an instrument has been developed and tested with three groups of engineering students. These students were all worked in design teams.

The first two tests measured performance only, while the third test measured both performance and attitude. Results of the first two iterations can be found in the proceedings of the 2002 American Society of Engineering Educators Conference. The final phase of validation of the model will be to determine students' learning.

The decision to develop a new instrument was made because no commercial questionnaires were available that tested for performance and attitude as dependent variables and the seven constructs as the independent variables.

The team effectiveness questionnaire was constructed using both nominal scales and interval scales. Nominal scales are used in the first part of the questionnaire to collect demographic information and some of the student preferences towards teaming. A five-point Likert scale ranging from "Strongly Agree" (1), to "Strongly Disagree" (5) is used as the interval scale for the second part of the questionnaire. The development of a new instrument presents the issues of reliability and validity.

Validity means that we can draw meaningful and justifiable inferences from scores about a sample or a population. There are several types of validity that can be reported: construct, criterion-referenced, and content validity. ${ }^{9}$

Construct validity is a determination of the significance, meaning, and purpose of use of scores from an instrument. The main question is whether the measures adequately provide a good operational definition of the variable. Evidence in this type of validity can be substantiated by using statistical procedures such as correlations or testing theories against scores, or nonstatistical procedures such as examining the values inherent in the interpretation of the scores, or the likely social consequences. ${ }^{9}$

Criterion-referenced validity is whether the scores from an instrument are a good predictor of some outcome they are expected to predict. Evidence in this type of validity is substantiated by selecting an outcome and correlating or relating the scores to it, or by selecting a future outcome and correlating the scores with it. ${ }^{9}$

Content validity is the extent to which the questions on the instrument and the scores from these questions are representative of all the possible questions that could have been asked about the content or skills. Evidence in this type of validity is substantiated by experts and available literature. ${ }^{9}$ At this time the only type of validation of this instrument the researchers 
will use is content validity. Future use of the instrument can provide data to test the other types of validity.

Reliability means that individual scores from an instrument should be nearly the same or stable on repeated administrations of the instrument, and that they should be free from sources of measurement error or consistent. ${ }^{9}$ Three basic features are used to select the types of reliability that can be reported: 1) the number of times the instrument is administered, 2) the number of versions of the instrument administered, and 3) the number of individuals who make an assessment of information. Based on these features, different types of reliability can be reported such as test-retest reliability, inter-rater reliability, and internal consistency.

Test-retest reliability examines the extent to which scores are stable over time from one test administration to another with the same sample. If the scores are reliable, then they relate (or correlate) at a high level, say a positive, reasonably high correlation of 0.6. Using this type of reliability, we only need one type of the instrument but practice can influence the scores. ${ }^{9}$

Inter-rater reliability applies to situations where the researcher is observing behaviors. Two or more individuals observe the behavior and their scores are related or correlated. The advantage of this approach is the ability to collect scores from more than one individual, but it requires the observers to negotiate outcomes and reconcile differences in their observations. ${ }^{9}$

In the internal consistency approach, scores from an instrument are reliable and accurate if they are consistent across the items on the instrument. The Cronbach's coefficient alpha can be used to test for internal consistency. If the items are scored as continuous variables (strongly agree to strongly disagree), Cronbach's alpha provides a coefficient to estimate consistency of scores on an instrument. ${ }^{9}$ For the reliability of this instrument the researchers will use test-retest and internal consistency with Cronbach's alpha.

Future work regarding the development and testing of the model includes the development and testing of additional assessment instruments as well as collaboration with industrial organizations to test the validity of the model in the workplace. As aforementioned, employers report that new engineers are technically astute but lack the skills deemed essential for achieving professional competence and for being effective as an engineer. Teaming skills are included in this list. The structure of the model with its initial focus on the individual and the individual's experience should be transferable in an industrial setting.

The second phase of the validation of the model is to develop and test a protocol for behavioral observation. The third phase of the model is to develop a methodology for determining if students working in teams learn more than those who do not. Research is currently underway to determine the best way to study team behaviors. Morgan et. al. argue that videotaping is an acceptable way to measure behavior but is timely and costly. ${ }^{10}$ They have developed the Critical Team Behaviors Form, which allows for the team convener to observe both the positive and negative behaviors of a team. ${ }^{10}$ The developers of this model are considering the development of an instrument like this for use with the seven constructs. The reliability and validity of this instrument will also have to be established.

"Proceedings of the 2002 American Society for Engineering Education Annual Conference \& Exposition Copyright (C) 2002, American Society for Engineering Education” 
While implementation of the final phase is not yet underway, a plan has been developed. The initial plan consists of selecting a service course such as intro to statistics or introduction to engineering economy and offering two sections: one taught utilizing teams and the other taught utilizing the traditional individualist method. In both courses, material content will be identical. However in team-based course, i.e. Homework, tests and projects will be in a team-based manner. At the end of the course students will be asked to demonstrate what they have learned via concept maps, vee diagram and knowledge tests. The hypothesis at that point will be: Students competing the course in the team based environment will learn more and be able to demonstrate it at a level greater than those in an individual based environment.

If this model is successfully applied to a team environment, post assessment should reveal: a) individually, team members grew in their understanding of the team constructs; b) the team as a whole grew in their understanding of team constructs and c) proper synergy of task and team process occurred.

Bibliography

1. The Green Report - Engineering Education for a Changing World, ASEE, October 1994, www.asee.org/pubs/html/greenworld.htm.

2. Engineering Criteria 2000, Third Edition, December 1997, www.abet.org/eac/eac2000.htm.

3. M.T. Brannick and C. Prince. (1997) An Overview of Team Performance Measurement. In M. T. Brannick, E. Salas, \& C. Prince (Eds.), Team Performance Assessment and Measurement (pp. 3-16). Mahwah, NJ: Lawrence Erlbaum Associates.

4. G. J. Salton, "Getting a Grip on Group Behavior", Industrial Management, pp. 26-33, November-December 2000 .

5. J. R. Katzenbach, and D. K. Smith, “The Discipline of Teams”, Harvard Business Review, pp. 111-120, MarchApril 1993.

6. A. Edmonson, "Psychological Safety and Learning Behavior in Work Teams", Administrative Science quarterly, vol. 44, no. 2, pp. 359-383, June 1999.

7. T. K. Capozzoli, "Resolving Conflict Within Teams", Journal for Quality and Participation, vol. 18 no. 7, pp. 28-31, December 1995.

8. S.G. Adams, "An Investigation of the Attributes Contributing to Team Effectiveness of Engineering and Science Faculty”, Texas A\&M University, Dissertation Abstracts International, 59, no. 08B, 1998.

9. B. B. Morgan, Jr., A.S. Glickman, E. A. Woodard, A. S. Blaiwes and E. Salas, "Measurement of Team Behaviors in a Navy Environment", (NTSV TR-86-014), November 1996.

10. J. W. Creswell, Educational Research: Planning, conducting, and evaluating quantitative and qualitative research. Upper Saddle River, NJ: Merrill/Prentice Hall.

"Proceedings of the 2002 American Society for Engineering Education Annual Conference \& Exposition Copyright @ 2002, American Society for Engineering Education” 
Biographical Information

\section{STEPHANIE G. ADAMS}

Dr. Adams received her Ph.D. from Texas A\&M University in Interdisciplinary Engineering. She holds a M.E. degree in Systems Engineering from University of Virginia and a B.S. degree in Mechanical Engineering from North Carolina A\&T State University. She is currently an Assistant Professor of Industrial and Management System Engineering at the University of Nebraska-Lincoln.

\section{LAURA C. SIMON VENA}

Laura holds both a M.S. and B.S. degree in Industrial and Management Systems Engineering from the University of Nebraska-Lincoln. She is currently pursuing employment opportunities in Madrid, Spain.

\section{BIANEY C. RUIZ-ULLOA}

Bianey is a doctoral student in Industrial Management Systems Engineering at the University of Nebraska-Lincoln. She holds a M.S. degree in Industrial and Management Systems Engineering from the University of NebraskaLincoln. She received a M.B.A. and B.S. in Industrial Engineering from the National University of Tachira Venezuela.

\section{FERNANDO PEREIRA}

Fernando recently completed a M.S. degree in Industrial and Management Systems Engineering, with a minor in Business Management from the University of Nebraska-Lincoln. He received B.S. in Industrial \& Management Systems Engineering Institution Tecnologico y de Estudios Superiores de Monterrey. 